\title{
ROLE OF CONTACT WITH TUBERCULOUS PATIENTS IN CASES OF TUBERCULOUS CERVICAL LYMPHADENITIS
}

\author{
Baskota D K*, Amatya R C M*, Shrivastav R P*, Sinha B K
}

\section{ABSTRACT}

A prospective, analytical and cross-sectional study to find out the role of contact with tuberculous patients during the process of development of Tuberculous Cervical Lymphadenitis was currently carried out in the Department of ENT- Head \& Neck Surgery of Tribhuvan University Teaching Hospital Kathmandu, Nepal. Altogether 103 cases of histopathologically confirmed cases of Tuberculous Cervical Lymphadenitis of more than six weeks of duration were included in the study during the period of one year from March, 2000 to February, 2001.

History of contact with tuberculous patients in the past during the development of the disease process was found to be positive in 19(18.4\%) of the 103 cases. In rest of the 84 cases history of contact with tuberculous patients was found to be negative $(\mathbf{8 1 . 6 \% )}$ ).

The result of this study so far indicates that there is a minimal role of contact with tuberculous patients for the development of tuberculous cervical lymphadenitis. Although tuberculosis is known as a chronic communicable disease, in our study majority cases of Tuberculous Cervical Lymphadenitis did not give any history of contact with tuberculous patients in the past.

\section{Key Words: Tuberculous cervical lymphadenitis, tuberculous patients, communicable disease.}

\section{INTRODUCTION}

Tuberculosis is one of the commonest chronic communicable diseases in the developing countries of the world including Nepal. It is still a major cause of disability and premature death throughout most of the world today. Estimates by the WHO place tuberculosis as the leading cause of adult death due to any single pathogen. ${ }^{1}$ Despite the decline of pulmonary tuberculosis in the western world; the incidence of cervical mycobacterial infections has remained relatively unaffected. ${ }^{2}$

A survey was carried out by National Tuberculosis Centre (NTC), of Nepal in cooperation with Japanese expert team in 2000 which showed the annual risk of infection is $1.8 \%$ and
$45 \%$ of the total population are infected. Likewise, 80-90 thousand people have active tuberculosis, 44 thousand new cases occur annually and 20 thousand new positive (infectious) cases detected per year and three deaths occur in every 2 hours by tuberculosis. ${ }^{3}$

Thompson MM et al in their study found that peripheral tuberculous lymphadenopathy is the commonest form of extrapulmonary tuberculosis and the sites most commonly affected were the cervical lymph nodes. ${ }^{4}$

Tuberculosis is caused by bacteria belonging to the Mycobacterium Tuberculosis Complex. In most instances the tuberculous bacilli gain entrance through the tonsil of the

* TU Teaching Hospital, Maharajgunj, Kathmandu, Nepal.

Address for correspondence : $\quad$ Dr. D. K. Baskota

TU Teaching Hospital, Maharajgunj, Kathmandu, Nepal

Email: cpsp@healthnet.org.np 
corresponding side of the cervical lymphadenopathy. ${ }^{5}$ Infection entry through the carries teeth or gums, tonsil or adenoids involved the upper deep cervical nodes, where as involvement of lower cervical nodes indicates infection commonly from the apex of the corresponding lungs. ${ }^{6}$ The tuberculous cervical lymphadenitis is usually developed in four different stages after sedimentation of tubercle bacilli in the corresponding lymph nodes and sign and symptoms are presented accordingly.

1. Stage of lymphadenitis: inflammation inside the lymph node"lymphadenitis".

2. Stage of periadenitis: inflammation around the lymph node "matted node".

3. Stage of caseation: formation of cold abscess. "Collar- stud abscess".

4. Stage of ulceration/sinus formation: draining caseated material from sinus.

Tuberculous cervical lymphadenitis is usually confirmed by the histologically presence of caseating granulomata and acid fast bacilli. ${ }^{7}$ The disease is treated with combination of multiple anti-tuberculous drugs either 6 months or 9 months regimen. Most clinicians agree that anti-tuberculous chemotherapy is the definite modality of treatment for tuberculous lymphadenitis ${ }^{8}$. Similarly, Weiler Z. et al in their series found that anti-tuberculous chemotherapy with or without surgical excision of the involved cervical lymph nodes is the method of choice for treatment of this disease. ${ }^{9}$

\section{MATERIALS AND METHODS}

All patients having cervical lymphadenitis with more than six weeks of duration and without any active sign of inflammation, attending to the out-patient clinic of the Department of ENT-Head \& Neck Surgery of Tribhuvan University Teaching Hospital were selected randomly for the study during the period of one year from March, 2000 to February, 2001.

Similarly, patients having similar problems, referred from other departments of the same institute were also selected for the study, based on prior request and information. After proper history taking, basically emphasizing the history of contact with tuberculous patients in the past and clinical examination, all patients were advised for following investigations:

? Blood: for $\mathrm{Hb}, \mathrm{Tc}, \mathrm{Dc}$ and ESR.

? Mantoux test.

? X-ray of the chest PA view.

? Excisional biopsy of lymph nodes.

At the same time, take care of surgical wound was done and a course of prophylactic antibiotic along with antiinflammatory analgesics was advised after surgical excision of the lymph node. After this, all patients were advised for follow up with the reports of all advised investigations. Reports of all investigation were plotted in a special proforma which was designed for this study. Those patients who did not have tuberculosis in their lymph nodes by histopathological examination (HPE) and who were not sure about their contact with tuberculous patients in the past were excluded from the study.

All tuberculous positive patients were advised for short course anti-tuberculous chemotherapy (Rifampicine + Isoniazide + Ethambutol + Pyrazinamide for initial two months followed by Rifampicine + Isoniazide next four months). Follow up after two months and four months of anti-tuberculous chemotherapy was done. The age of the patients ranges from 9 years to 54 years and of ages from 20 years to 29 years found to be the maximum in numbers which is given below.

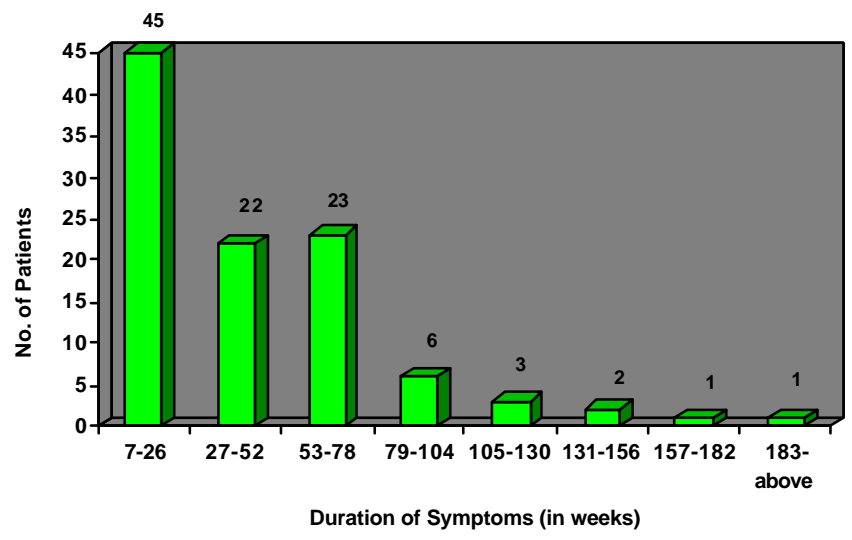

Fig. 1 : Distribution of duration of symptoms (in weeks)

Table I : Age distribution

\begin{tabular}{c|c|c}
\hline Age in years & No. of Patients & Percentage (\%) \\
\hline $0-9$ & 1 & 00.97 \\
\hline $10-19$ & 32 & 31.07 \\
\hline $20-29$ & 39 & 37.86 \\
\hline $30-39$ & 20 & 19.42 \\
\hline $40-49$ & 6 & 05.83 \\
$50-59$ & 5 & 04.85 \\
60 \& above & 0 & 00.00 \\
Total & $\mathbf{N = 1 0 3}$ & $\mathbf{1 0 0 \%}$ \\
\hline
\end{tabular}


Regarding sex, of the 103 patients of studied 51 were male and 52 were female.

In this study duration of cervical lymphadenitis ranged from 7 weeks to 234 weeks ( 4.5 years). The maximum number of patients (45) fallen in between 7 to 26 weeks of duration after the development of tuberculous cervical lymphadenitis.

Data obtained from all histopathologically confirmed cases of tuberculous cervical lymphadenitis and history of contact with tuberculous patients who could give their history confidently about their contact in the past were analyzed and conclusions were made accordingly.

\section{RESULTS}

As tuberculosis is a communicable disease, contact with known cases of tuberculosis (source) will play a great role during the development of the any form of tuberculous disease process. So the basic aim of this study is to find out the positive history of contact with known tuberculous patients in the past during the process of development of tuberculous cervical lymphadenitis. In our analysis, of the 103 patients, 19 gave the positive history of contact with tuberculous patients (18.4\%) where as 84 patients did not $(81.6 \%)$ give any history of contact with known source in the past. Positive history of contact with tuberculous patients is shown in the following figure.

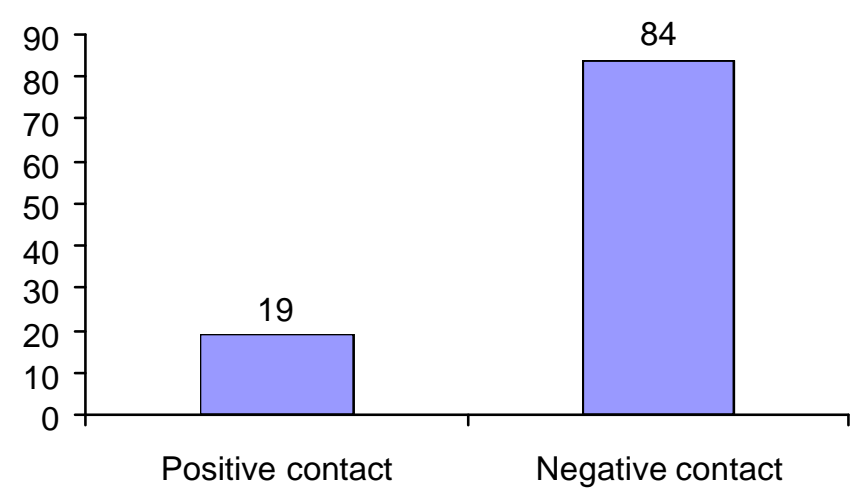

Fig. 3 : Role of contact with tuberculous patients

\section{DISCUSSION}

Tuberculosis is a chronic communicable disease and it has a significant role of contact with known tuberculous patients during the development of the disease process. But, in our study of the 103 patients, only 19 patients gave the history of contact with tuberculous patients (18.4\%). Majority of our patients, $84(81.6 \%)$ of the 103 , did not give the history of contact with the source i.e. known tuberculous patients.

Seth $\mathrm{V}$ et al found more or less similar incidence in their series of 113 cases. Family history of contact with known tuberculous patients was positive in 19 (17\%) of the 113 total cases. ${ }^{11}$

Possible causes behind this controversial observation are either majority of our patients are unable to know the source of the disease (tuberculous patients) or majority of tuberculous patients keep them secret if they suffered from tuberculosis due to various social problems.

Similarly, majority of our patients are unaware with significant role of contact with known tuberculous patients that may lead to develop any form of tuberculosis subsequently.

Likewise, due to illiteracy, proverty and lack of health awareness most of the patients can not give exact history and clinical information of their past regarding any disease process.

\section{CONCLUSIONS}

All clinical information and histopathological report of primarily involved cervical lymph nodes were thoroughly observed, analysed and compared. During history taking and collecting clinical information regarding the disease, more emphasis was given to find out the history of contact with tuberculous patients in the past. After thorough analysis of obtained data and clinical information following conclusions were made.

1. There is a minimal role of contact with tuberculous patients during the development of tuberculous cervical lymphadenitis.

2. Majority of our patients are unaware with significant role of contact with tuberculous patients that may lead to develop any form of tuberculosis subsequently including tuberculous cervical lymphadenitis.

3. Majority of our patients least bother seeking any medical advice until and unless the disease process including tuberculous cervical lymphadenitis does not create any clinical symptoms.

\section{REFERENCES}

1 Kochi A The Gobal Tuberal osi S S tuation and the NewCortrd Strategy of the VAD Tubercle. 1991; 71: 1

2 Mndids S; Frenkid S; Yoskovitch A B ack M. Mycobacterial Inf ecti ons of the read \& Neck. Ool aryngol ogy-Head \& Neck Surgery. 1993; 109: 427-33.

3 Adk M Tubercul osi s Contrd Strategy in Nepd. Semner and Vorkshop on Nati onal Tubercul osi s Contrd Programe, Nbv. 2000. 
4 Thonpson $M$ M Under nood $M$; Sayers $R D$, Dooker an $K A$; Bel I PR Peri pheral Tubercul as Lyrphadenopathy: A Revi ew of 67 Cases. Briti sh J arnal of Surgery. 1992; 79. 763-4.

5 Davi d Hoverd Valerie J. Lund Pharynx, Larynx and Neck In RCC Russel I eds. Bail ey and Love's Short Practi ce of Surgery. London; Arnol d; 2000: 704.

6 APMForrest. Pri nci pl es and Practi ce of Surgery. $6^{\text {th }}$ ed Ed nburgh; Churchi I Li vi ngstone. 1991: 322

7. APM Forrest eds. Pri nci pl es and Practi ce of Surgery. Ed nourgh; Curchi I Li vi ngstone. 1991: 322

8 Darrel I H Jdn LB Eid ogy of I nfecti as Dseeses of the Ypper Respi rat ory Tract. I n: J ohn J. Bal I enger eds.
Q orhi nol aryngol ogy Head \& Neck Surgery. Phi I adel phi a, WMl I ans \& WVI kins. 1996: 78.

9 Dei tel $M$ Bendago $M$ Kraj den S; Ronal d AC; Bor ovy Z. Modern nanagenent of cervi cal scr of ul a. Head \& Neck. 1989; 11: $60-66$.

10. W Wiler Z; Nel I y P; Baruchi $n$ AM Oren S. Dagnosi s and treetnent of cervical tubercul as I yrphaderi tis. J arral of oal NAxill of ac Surg 2000, 58: 477- 81

11. Seth V, Kabra SK J a n Y, Senmal $\mathbb{Q}$, Mkhopadhaya S, J ensen R Tubercular Lynphaderiti s: Ci i i cal Neri festations. I nd an J ournal of Pediatri cs. 1995; 6: 565-70.

$$
\text { \& } 25
$$

